\title{
On Terms
}

\section{On Citing the Literature}

\author{
A. Charles Catania \\ University of Maryland Baltimore County
}

\begin{abstract}
Some outlandish examples are used to support the argument that literature citations should be treated as references to documents and not references to individuals. Different consequences for scientific behavior are implicit in the alternative usages.
\end{abstract}

A literature citation refers not to a person but to a document. When we cite an article, our response is occasioned by the text, and not by its author. Some implications of this feature of citations are merely grammatical. For example, should a citation always take the singular even if it includes more than one author, and should citations of multiple works by a single author always take the plural?

Daly and Knightly (1978) is a timely work on circadian rhythms. Heavyhand $(1977,1979)$ are indispensable for every practitioner's library; although the recent abridgment simply reproduces every fifth page of the original work, it also adds an index and thumbnail sketches of prominent investigators.

Similarly, what prepositions are implied by the alternative usages?

A miniaturization of the famous hedge maze at Hampton Court for studies of the latent learning in rats was described by Alley (1971). When performances of free-moving rats were compared with those of rats transported through the maze on electric trains in the experiments of de Sac (1971), these apparatuses came to be called Lionel Hampton Court Mazes.

Other implications of these usages, however, are more far-reaching than such grammatical dilemmas. Consider this example:

Knotts (1965) established sign language in an octopus. Boltz (1969) taught a similar vocabulary to a chimpanzee. Knotts and Boltz (1972) provided transcripts of octopus-chimpanzee conversations. On the basis of a sequential analysis of these data, Patio (1974) wrote a transformational grammar and concluded that the octopus behavior could not be called verbal.

Readers familiar with Current Contents will recognize the influence of editorials by Eugene Garfield of the Institute for Scientific Information. No one will recognize the influence of Robert $R$. Provine (but it is there). For reprints, write the author at the Department of Psychology-UMBC, 5401 Wilkens Avenue, Catonsville, MD 21228.
This passage differs critically from the following:

Fast running was shaped in the tortoise (Sopp, 1959). The rate of this responding did not approach that obtained with hares (Sopp, 1961). Running rate depends on an extensive phylogenic history (Tanner, 1969), but these species-specific behavior patterns evolved because of limits on tortoise respiration. Tortoises lack hare's breath (Sopp \& Fabe, 1968).

The two passages differ in more than their content. In the first example, researchers are the subjects of each sentence. In the second, the sentences concern properties of behavior. The style of the former encourages questions about which researcher hadpriority and about who was right and who was wrong. The style of the latter encourages questions about the way things are and how they got to be that way.

If we support the argument that science should not be a matter of personalities, we should favor the usage that puts the investigator in parentheses, at the end of the relevant phrase. The citation supports the sentence. It is not what the sentence is about, but it provides some of the evidence on the basis of which the sentence was written. This does not imply that we should avoid treating behavior analysis as a human endeavor. It remains important that we recognize the human biases that enter into interpretations of data and applications of behavioral principles, especially because the literature can be cited inappropriately no matter what the accepted usage. The responsibility to weigh the evidence in both an article and the works it cites continues to rest with the reader. Fortunately, the credibili- 
ty of some passages does not depend on their citations:

In a contingency-management system that arranged points for the outputs of Detroit autoworkers, autoshaping was independent of the correlation between points and salaries. Zakrin (1938) showed that the results depended on averaging across individuals: the points that maintained the behavior of some workers were for others only token reinforcers.

For some types of stylistic guidelines, it is easy to obtain consensus. For example, it is typically agreed that short words and sentences are preferable to equivalent long ones (as when we substitute "the key was lit" for "the key was illuminated" or "the session ended for "the session terminates," or as when an editor deletes uninformative phrases such as "It has been reported that ..." and "The present data show that . . .'). The case for the conversion of nouns to verbs and passives to actives can be made by demonstrations of the resulting clarification of texts (as when we rewrite the preceding as "demonstrating how texts are clarified makes the case for converting nouns to verbs and passives to actives.")

Some redundancies stand on the borderline between matters of style and matters of technical usage (as when we note that "the acquisition of autoshaping was retarded . . ." could have been written as "autoshaping occurred slowly ....'). Even so, the consequences of such usages are usually hard to identify. When authors neglect matters of style, the consequences for a reader may be that some articles take a little longer to get through than would otherwise be the case, and those for the authors may be that the reader will be a little less likely to read their articles in the future. These consequences are relatively trivial compared to those of making investigators rather than their findings the subjects of a text. Such relations should remind us how inextricably style can be tied to substance. Let us put authors in their proper places. First comes behavior. The rest should be parenthetical.

\section{REFERENCES}

Alley, T. P. An history of maze learning. Knossos: Labyrinth Books, 1971.

Boltz, H. Language in octopus: the chimpanzee connection. Pseudopod Science, 1969, 512, 888-968.

Daly, P., \& Knightly, I. Circadian rhythms. Greenwich: Sundial Publishers, 1978.

de Sac, C. Training the rat to keep track of switching behavior. Journal of Physiological and Comparative Psychonomy, 1977, 77, 101-111.

Heavyhand, L. (Ed.) Handbook of the analysis of behavior. Palm Springs: Digital Press, 1977.

Heavyhand, L. (Ed.) Fingerbook of the analysis of behavior. Palm Springs: Digital Press, 1979.

Knotts, T. Gestural language in octopus. Orlando: Porpoise Books, 1965.

Knotts, T., \& Boltz, H. The eight-fold way. Honolulu: Octagon Books, 1972.

Patio, S. H. Num: an octopus who learned sign language. Lake Tahoe: Parrot Press, 1974.

Sopp, A. The differential reinforcement of accelerated locomotion in the common tortoise. Journal of the Analysis of Experimental Behavior, $1959,2,0-40$.

Sopp, A. The differential reinforcement of accelerated locomotion: systematic replication with a new species. Journal of the Analysis of Experimental Behavior, 1961, 4, 0-120.

Sopp, A \& Fabe, L. The evolution of ontogenic behavior. Journal of General Experimental Psychonomy: Animal and Human Memory, Skill, Perception, Behavior, and Higher Mental Processes, 1968, I, 117-120.

Tanner, B. F. Are theories of evolution necessary? Psychonomical Review, 1969, 57, 193-216.

Zakrin, A. The ABADABA simultaneous-treatment design in applied settings. In $R$. Backhand (Ed.) Recent advances in methodological progress: proceedings of a sponsored retreat. Dunwich, N.H.: Miskatonic University Press, 1938. 